\title{
Assessment of validity of the 'Culprit Score' for predicting the culprit artery in patients with acute inferior wall myocardial infarction
}

\author{
Karim Adel Ellakany ${ }^{(1)}$, Ibrahim Abdelfattah Yasin ${ }^{(2)}$, \\ Moustafa Ibrahim Mokarrab ${ }^{(2)}$, Mansour Mohamed Sallam ${ }^{(2)}$ \\ 1- Department of Cardiology, Damanhour Teaching Hospital, 2-Department of Cardiology, Faculty of \\ Medicine, Al-Azhar University
}

Corresponding Author: Karim Adel Ellakany, Phone: 01002839070, email: karimellakany@ gmail.com

\begin{abstract}
Background: Acute myocardial infarction is still a major health problem inspite of the impressive stride in diagnosis and treatment. Therefore, the early diagnosis and proper management is an important challenge. The identification of infarct related artery and site of occlusion in inferior wall myocardial infarction is extremely important to predict complications.

Aim of the work: evaluating the use of 'culprit score' for prediction of the culprit artery in inferior wall MI

Methods: This was a prospective observation study that was done from June 2017 to July 2018 and included 100 patients presented to the coronary care unit at Al-Azhar University Hospitals and National Heart Institute with inferior wall myocardial infarction. All patients were subjected to: history taking, clinical examination, ECG, cardiac enzymes, echocardiography and coronary angiography. Culprit Score is defined as: [(II -V2) / (III + V1 - aVL)] by measuring ST elevation in leads (II, III) and ST displacement in leads (V1, V2, AVL).

Results: Mean age of patients involved in the study was $56.42+10.78$ years with $80 \%$ of patients being male. The sensitivity and specificity, positive predictive value (PPV) and negative predictive value (NPV) of Culprit Score $\leq \mathbf{0 . 5}$ to predict proximal RCA occlusions were 79.49 \%, 86.89\%, $79.49 \%$, and $86.89 \%$, respectively and $\mathbf{0 . 5}$ to $\leq \mathbf{1 . 5}$ to predict distal RCA occlusions were $78.13 \%, 86.76 \%$, $73.53 \%$, and $89.39 \%$, respectively; and score $>\mathbf{1 . 5}$ to predict LCX occlusions were $79.5 \%$ and 86.9 $\% ; 78.1 \%$ and $86.7 \%$; and $75.8 \%$ and $92.9 \%$, respectively.

Conclusion: Culprit score could reliably predict the site of occlusion in inferior wall myocardial infarction.
\end{abstract}

Keywords: Culprit Score, predicting, culprit artery, acute inferior wall myocardial infarction.

\section{Introduction}

Worldwide, coronary artery disease is the single most common cause of death and its frequency is increasing. However, in Europe, there has been a trend to reduce coronary artery disease mortality over the past 30 years ${ }^{(1)}$.

Myocardial infarction could be caused by an occlusive coronary thrombus at the site of a pre-existing atherosclerotic plaque. In rare cases, infarction may result from prolonged coronary vasospasm, inadequate myocardial blood flow or increased myocardial demand ${ }^{(15)}$.

The electrocardiogram (ECG) is being used for decades to diagnose acute myocardial infarction in the patients with chest pain because it is reliable and inexpensive tool. More recently, an emphasis has been made on ECG features that allow better determination of the site of occlusion and thereby better estimation of the size of the area at risk and prediction of complications ${ }^{(11)}$.

Accepted: 26/10/2018

The culprit artery of ST-segment elevation myocardial infarction (STEMI) is usually the left anterior descending artery (LAD) in anterior STEMI. But inferior STEMI, the culprit artery is either the right coronary artery (RCA) or left circumflex (LCx) artery. Various ECG criteria were suggested to predict the culprit artery based on analysis of STsegment elevation and depression in different ECG leads ${ }^{(2)}$.

The aim of this study is evaluating the use of Culprit Score to predict the culprit artery and site of occlusion in patients with inferior wall myocardial infarction.

\section{Patients and Methods}

This prospective observational study involved 100 patients from the patients admitted to Al-Azhar University Hospital and National Heart Institute with the diagnosis of 
inferior wall myocardial infarction during the period from June 2017 to July 2018.

All patients presented, within $24 \mathrm{~h}$ from symptom onset with ECG, with at least $1 \mathrm{~mm}$ ST elevation in at least 2 of the inferior leads (II, III, and aVF). coronary angiography was done during their hospitalization.

We excluded Bundle branch block, ventricular pacing, ventricular hypertrophy and pericarditis. Also, patients with history of previous myocardial infarction, previous percutaneous coronary intervention (PCI) or coronary artery bypass graft (CABG) surgery were excluded.

History was taken including age, sex, smoking, Hypertension, diabetes mellitus, coronary artery disease, dyslipidemia, family history of coronary artery disease. The study was approved by the Ethics Board of AlAzhar University.

We did full clinical examination including heart rate, rhythm, pulse volume, respiratory rate, blood pressure, temperature, pulmonary rales, additional heart sounds, murmurs and pericardial rub.

Twelve leads ECG was obtained to confirm the diagnosis with at least $1 \mathrm{~mm} \mathrm{ST}$ elevation in at least 2 of the inferior leads (II, III, and aVF). ST changes were measured at 80 $\mathrm{ms}$ from $\mathrm{J}$ point, and the TP segment was considered the isoelectric line of the ECG.

Echocardiography was performed using standard views such as parasternal long and short, subcostal and apical window to assess Left ventricular ejection fraction, regional wall motion abnormalities, right ventricular functions by TAPSE (Tricusped annulus plane systolic excursion) and valvular dysfunction.

The infarct-related artery was identified either by total occlusion or a stenosis $>70 \%$ of diameter of the LCX or RCA or their branches, or presence of an intraluminal thrombus. Proximal RCA was defined as the coronary segment proximal to the first RV branch regarding to the American College of Cardiology/American Heart Association guidelines ${ }^{(3)}$.

Laboratory investigations had been done including liver functions, kidney functions, lipid profile and Serum cardiac biomarkers that include serial measurement of cardiac troponin I (CTnI), myocardial band of creatine kinase (CK-MB) and creatine kinase (CK).

Culprit Score, is defined as: [(II -V2)/ $($ III + V1 $-\mathbf{a V L})$ ] by measuring ST elevation in leads (II, III) and ST displacement in leads (V1, V2, AVL) ${ }^{(13)}$.

Culprit Score $\leq \mathbf{0 . 5}$ for prediction of proximal RCA occlusions; $\mathbf{0 . 5}$ to $\leq \mathbf{1 . 5}$ for prediction of distal RCA occlusions; and score $>\mathbf{1 . 5}$ for prediction of LCX occlusion. If the denominator was $\leq 0$ and the numerator was $>0$, then the Culprit Score was arbitrarily considered to be $\mathbf{5}$ and LCX was considered to be the culprit artery.

Data were analyzed via Statistical program for social science (SPSS)version 20.0. Quantitative data were expressed as mean \pm standard deviation (SD) while qualitative data were expressed as and percentage frequency. Independent samples t-test of significance was used when comparing between two means. Chisquare $(\chi 2)$ test of significance was used in order to compare proportions between two qualitative parameters.

\section{Results}

This is a prospective cross sectional observational study that included 100 patients who were admitted to Al- Azhar University Hospitals and National Heart Institute with acute inferior wall myocardial infarction during the period from June 2017 to July 2018.

The mean age was $56.42 \pm 10.78$ years (ranged from 24-81 years) with male predominance $80 \%$ (80 patients).

Table (1): Distribution of the studied cases as regards age, gender.

\begin{tabular}{|c|c|c|c|c|c|c|c|c|c|c|}
\hline & \multicolumn{2}{|c|}{$\begin{array}{c}\text { Total } \\
(\mathbf{n}=\mathbf{1 0 0})\end{array}$} & \multicolumn{2}{|c|}{$\begin{array}{c}\text { Prox RCA } \\
(\mathbf{n}=39) \\
\end{array}$} & \multicolumn{2}{|c|}{$\begin{array}{c}\text { Mid RCA } \\
(n=32)\end{array}$} & \multicolumn{2}{|c|}{$\begin{array}{c}\text { LCX } \\
(\mathbf{n}=29) \\
\end{array}$} & \multirow{2}{*}{$\begin{array}{c}\text { Test of } \\
\text { Sig. }\end{array}$} & \multirow{2}{*}{$\mathbf{p}$} \\
\hline & No. & $\%$ & No. & $\%$ & No. & $\%$ & No. & $\%$ & & \\
\hline $\begin{array}{c}\text { Gender } \\
\text { Male } \\
\text { Female } \\
\end{array}$ & $\begin{array}{l}80 \\
20\end{array}$ & $\begin{array}{l}80.0 \\
20.0 \\
\end{array}$ & $\begin{array}{l}29 \\
10\end{array}$ & $\begin{array}{l}74.4 \\
25.6 \\
\end{array}$ & $\begin{array}{c}27 \\
5\end{array}$ & $\begin{array}{l}84.4 \\
15.6\end{array}$ & $\begin{array}{c}24 \\
5 \\
\end{array}$ & $\begin{array}{l}82.8 \\
17.2\end{array}$ & $\begin{array}{l}\square \square \square \\
\square .296 \\
\end{array}$ & 0.523 \\
\hline $\begin{array}{c}\text { Age }(\text { years }) \\
\text { Min. }- \text { Max. } \\
\text { Mean } \pm \text { SD. } \\
\text { Median }\end{array}$ & \multicolumn{2}{|c|}{$\begin{array}{c}24.0-81.0 \\
56.42 \pm 10.78 \\
56.0\end{array}$} & \multicolumn{2}{|c|}{$\begin{array}{c}24.0-81.0 \\
58.05 \pm 10.71 \\
57.0\end{array}$} & \multicolumn{2}{|c|}{$\begin{array}{c}31.0-72.0 \\
55.44 \pm 9.77 \\
55.0\end{array}$} & \multicolumn{2}{|c|}{$\begin{array}{c}27.0-78.0 \\
55.31 \pm 11.98 \\
55.0\end{array}$} & $\begin{array}{c}F= \\
0.729\end{array}$ & 0.485 \\
\hline
\end{tabular}


Assessment of validity of the 'Culprit Score' for predicting the culprit artery in patients...

$\mathrm{p}: \mathrm{p}$ value for comparing between the three groups

In our study, there was no significant statistical difference in the studied groups as regards the risk factors for IHD including ; HTN, DM, dyslipidemia, history of coronary artery disease or + ve family history of coronary artery disease with one exception which was smoking. (Table 2 and 3):

Table (2): Comparison between our study groups according to risk factors

\begin{tabular}{|c|c|c|c|c|c|c|c|c|c|c|}
\hline \multirow[t]{2}{*}{ Risk Factors } & \multicolumn{2}{|c|}{$\begin{array}{c}\text { Total } \\
(\mathbf{n}=\mathbf{1 0 0})\end{array}$} & \multicolumn{2}{|c|}{$\begin{array}{c}\text { Prox RCA } \\
(n=39)\end{array}$} & \multicolumn{2}{|c|}{$\begin{array}{c}\text { Mid RCA } \\
(\mathbf{n}=32)\end{array}$} & \multicolumn{2}{|c|}{$\begin{array}{c}\text { LCX } \\
(n=29)\end{array}$} & \multirow[t]{2}{*}{$\chi^{2}$} & \multirow[t]{2}{*}{$\mathbf{p}$} \\
\hline & No. & $\%$ & No. & $\%$ & No. & $\%$ & No. & $\%$ & & \\
\hline$\overline{\text { HTN }}$ & 50 & 50.0 & 22 & 56.4 & 15 & 46.9 & 13 & 44.8 & 1.076 & 0.584 \\
\hline DM & 41 & 41.0 & 17 & 43.6 & 12 & 37.5 & 12 & 41.4 & 0.272 & 0.873 \\
\hline FH & 10 & 10.0 & 2 & 5.1 & 3 & 9.4 & 5 & 17.2 & 2.609 & ${ }^{\mathrm{MC}} \mathrm{p}=0.235$ \\
\hline Dyslipidemia & 16 & 16.0 & 8 & 20.5 & 5 & 15.6 & 3 & 10.3 & 1.284 & 0.526 \\
\hline Others & 2 & 2.0 & 0 & 0.0 & 1 & 3.1 & 1 & 3.4 & 1.645 & ${ }^{\mathrm{MC}} \mathrm{p}=0.516$ \\
\hline
\end{tabular}

$\chi^{2}$ : Chi square test MC: Monte Carlo

$\mathrm{p}: \mathrm{p}$ value for comparing between the three groups

Table (3): Comparison between the different studied groups according to smoking

\begin{tabular}{|c|c|c|c|c|c|c|c|c|c|c|}
\hline \multirow[t]{2}{*}{ Smoking } & \multicolumn{2}{|c|}{$\begin{array}{c}\text { Total } \\
(\mathbf{n}=\mathbf{1 0 0})\end{array}$} & \multicolumn{2}{|c|}{$\begin{array}{c}\text { Prox RCA } \\
(\mathbf{n}=39)\end{array}$} & \multicolumn{2}{|c|}{$\begin{array}{c}\text { Mid RCA } \\
(\mathrm{n}=32)\end{array}$} & \multicolumn{2}{|c|}{$\begin{array}{c}\text { LCX } \\
(n=29)\end{array}$} & \multirow[t]{2}{*}{$\chi^{2}$} & \multirow[t]{2}{*}{$\mathbf{p}$} \\
\hline & No. & $\%$ & No. & $\%$ & No. & $\%$ & No. & $\%$ & & \\
\hline Non-smoker & 26 & 26.0 & 12 & 30.8 & 8 & 25.0 & 6 & 20.7 & \multirow{3}{*}{$10.603^{*}$} & \multirow{3}{*}{$0.031^{*}$} \\
\hline Smoker & 52 & 52.0 & 13 & 33.3 & 20 & 62.5 & 19 & 65.5 & & \\
\hline Ex-smoker & 22 & 22.0 & 14 & 35.9 & 4 & 12.5 & 4 & 13.8 & & \\
\hline
\end{tabular}

Regarding echocardiography, the mean LVEF of all patients involved in the study was $(55.70 \pm$ $9.75 \%$ ). The difference between the groups didn't reach a statistically significant value ( $\mathrm{P}$ value $>0.05$ ).

(Figure 1)

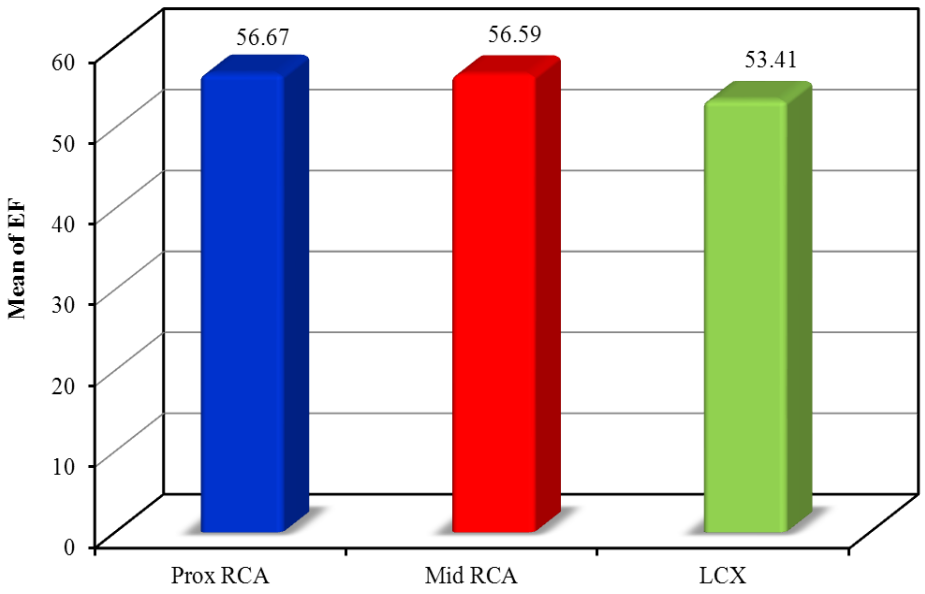

Figure (1): Comparison between the different studied groups according to EF

In contrast, there was a significant statistical difference in the studied groups as regards TAPSE. (Table 4).

Table (4): Comparison between the different groups according to TAPSE

\begin{tabular}{|c|c|c|c|c|c|c|c|c|c|c|}
\hline & \multicolumn{2}{|c|}{$\begin{array}{c}\text { Total } \\
(\mathbf{n}=\mathbf{1 0 0})\end{array}$} & \multicolumn{2}{|c|}{$\begin{array}{c}\text { Prox RCA } \\
(\mathrm{n}=39)\end{array}$} & \multicolumn{2}{|c|}{$\begin{array}{c}\text { Mid RCA } \\
(\mathrm{n}=32)\end{array}$} & \multicolumn{2}{|c|}{$\begin{array}{c}\text { LCX } \\
(\mathbf{n}=29)\end{array}$} & \multirow{2}{*}{$\begin{array}{c}\text { Test of } \\
\text { Sig. }\end{array}$} & \multirow{2}{*}{$\mathbf{p}$} \\
\hline & No. & $\%$ & No. & $\%$ & No. & $\%$ & No. & $\%$ & & \\
\hline $\begin{array}{c}\text { TAPSE } \\
\leq 16 \\
>16\end{array}$ & $\begin{array}{l}21 \\
79\end{array}$ & $\begin{array}{l}21.0 \\
79.0\end{array}$ & $\begin{array}{l}14 \\
25\end{array}$ & $\begin{array}{l}35.9 \\
64.1\end{array}$ & $\begin{array}{c}5 \\
27\end{array}$ & $\begin{array}{l}15.6 \\
84.4\end{array}$ & $\begin{array}{c}2 \\
27\end{array}$ & $\begin{array}{c}6.9 \\
93.1\end{array}$ & $\begin{array}{c}\chi^{2}= \\
9.251^{*}\end{array}$ & $0.010^{*}$ \\
\hline $\begin{array}{l}\text { Min. - Max. } \\
\text { Mean } \pm \text { SD. } \\
\text { Median } \\
\end{array}$ & \multicolumn{2}{|c|}{$\begin{array}{c}12.0-25.0 \\
18.60 \pm 3.10 \\
19.0 \\
\end{array}$} & \multicolumn{2}{|c|}{$\begin{array}{c}12.0-22.0 \\
17.0 \pm 3.05 \\
17.0 \\
\end{array}$} & \multicolumn{2}{|c|}{$\begin{array}{c}13.0-25.0 \\
18.75 \pm 2.55 \\
18.50 \\
\end{array}$} & \multicolumn{2}{|c|}{$\begin{array}{c}14.0-24.0 \\
20.59 \pm 2.54 \\
21.0 \\
\end{array}$} & $\begin{array}{c}H= \\
22.963^{*}\end{array}$ & $<0.001^{*}$ \\
\hline Sig. bet. Groups & & & \multicolumn{6}{|c|}{$\mathrm{p}_{1}=0.033^{*}, \mathrm{p}_{2}<0.001^{*}, \mathrm{p}_{3}=0.009^{*}$} & & \\
\hline
\end{tabular}

$\chi^{2}$ : Chi square test 
H: H for Kruskal Wallis test, Pairwise comparison bet. each 2 groups was done using Post Hoc Test (Dunn's for multiple comparisons test)

$\mathrm{p}$ : $\mathrm{p}$ value for comparing between the three groups

$\mathrm{p}_{1}$ : $\mathrm{p}$ value for comparing between the Prox RCA and Mid RCA

$\mathrm{p}_{2}$ : $\mathrm{p}$ value for comparing between the Prox RCA and LCX

$\mathrm{p}_{3}$ : $\mathrm{p}$ value for comparing between the Mid RCA and LCX

*: Statistically significant at $\mathrm{p} \leq 0.05$

In our study, the difference in mean heart rate between the studied groups was statistically significant $(\mathrm{P}$ value $<0.05)$. Table $(5)$

Table (5): Heart rate of the studied cases in relation to the culprit artery

\begin{tabular}{|c|c|c|c|c|c|c|}
\hline & $\begin{array}{c}\text { Total } \\
(\mathbf{n}=\mathbf{1 0 0})\end{array}$ & $\begin{array}{c}\text { Prox RCA } \\
(\mathrm{n}=39)\end{array}$ & $\begin{array}{c}\text { Mid RCA } \\
(\mathrm{n}=\mathbf{3 2})\end{array}$ & $\begin{array}{c}\text { LCX } \\
(n=29)\end{array}$ & Test of Sig. & $\mathbf{p}$ \\
\hline $\begin{array}{l}\text { Heart rate } \\
\text { Min. - Max. }\end{array}$ & $34.0-90.0$ & $34.0-82.0$ & $54.0-90.0$ & $56.0-90.0$ & & \\
\hline Mean \pm SD & $71.45 \pm 12.0$ & $66.49 \pm 13.96$ & $74.87 \pm 9.89$ & $74.34 \pm 8.93$ & $\mathrm{~F}=6.042^{*}$ & $0.003^{*}$ \\
\hline Median & 74.0 & 70.0 & 75.50 & 76.0 & & \\
\hline Sig. bet. groups & & \multicolumn{3}{|c|}{$\mathrm{p}_{1}=0.008^{*}, \mathrm{p}_{2}=0.017^{*}, \mathrm{p}_{3}=0.982$} & & \\
\hline
\end{tabular}

There was no statistically significant difference between both RCA and LCX cases regarding rhythm abnormalities ( $\mathrm{P}$ value $>0.05)$.

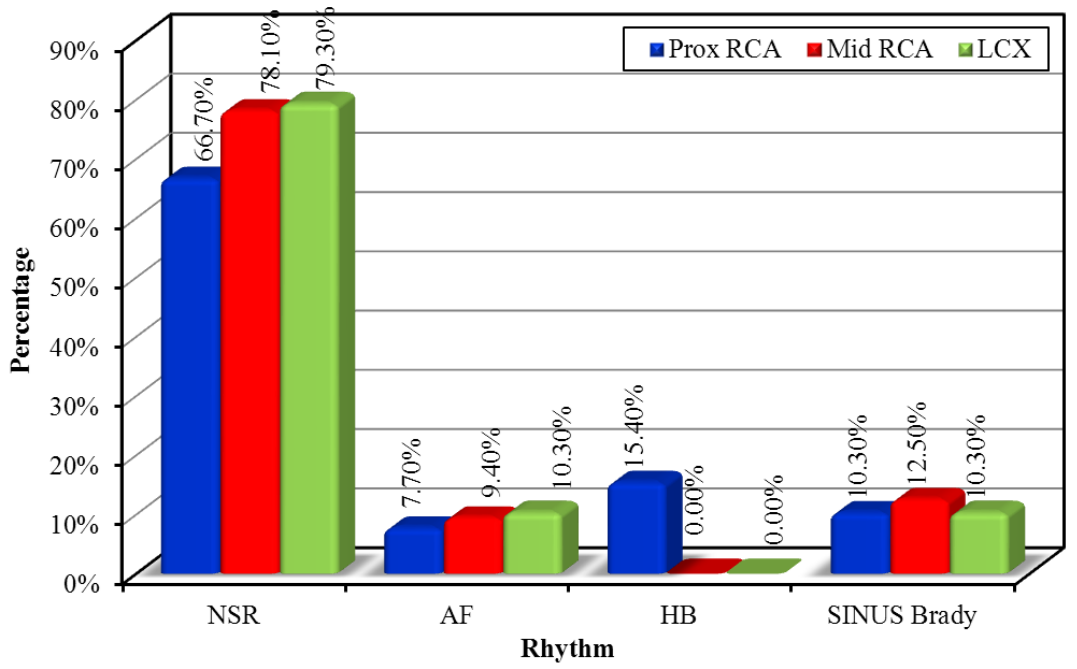

Figure (2): Comparison between the study groups according to rhythm

In this study population, the number of patients who had RCA lesion was 71, of which 39 had proximal RCA lesion and 32 had distal RCA lesion. Rest of the 29 patients had circumflex artery lesion Figure (3).

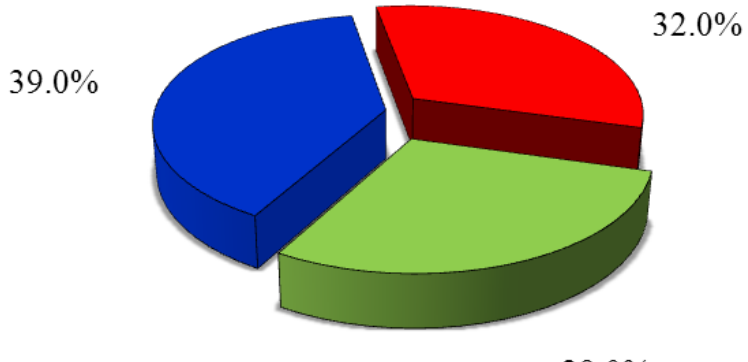

$29.0 \%$

Prox RCA $\quad$ Mid RCA $\quad$ LCX

Figure (3): Distribution of the studied cases according to Culprit lesion $(n=100)$

This study showed that the difference in Culprit Score in between the groups was statistically significant $(\mathrm{P}$ value $<0.05)$. 
Assessment of validity of the 'Culprit Score' for predicting the culprit artery in patients...

Table (6): Culprit score results in relation to the culprit artery

\begin{tabular}{|c|c|c|c|c|c|c|}
\hline \multirow[t]{2}{*}{ Culprit score } & \multicolumn{2}{|c|}{$\begin{array}{c}\text { Prox RCA } \\
(\mathbf{n}=39)\end{array}$} & \multicolumn{2}{|c|}{$\begin{array}{c}\text { Distal RCA } \\
(\mathbf{n}=32)\end{array}$} & \multicolumn{2}{|c|}{$\begin{array}{c}\text { LCX } \\
(n=29)\end{array}$} \\
\hline & No. & $\%$ & No. & $\%$ & No. & $\%$ \\
\hline$\leq 0.5$ & 31 & 79.5 & 5 & 15.6 & 3 & 10.0 \\
\hline $0.5-1.5$ & 5 & 12.8 & 25 & 78.1 & 4 & 13.8 \\
\hline$>1.5$ & 3 & 7.7 & 2 & 6.3 & 22 & 75.9 \\
\hline$\kappa(\mathbf{p})$ & \multicolumn{6}{|c|}{$0.667^{*}\left(<0.001^{*}\right)$ Good agreement } \\
\hline
\end{tabular}

In this study the sensitivity, specificity, positive predictive value (PPV) and negative predictive value (NPV) of the Culprit Score are shown in table (7).

Table (7): Accuracy of Culprit Score

\begin{tabular}{|l|c|c|c|c|c|}
\hline & Sensitivity & Specificity & PPV & NPV & Accuracy \\
\hline $\begin{array}{l}\text { Culprit Score } \leq \mathbf{0 . 5} \text { to predict proximal RCA } \\
\text { occlusion }\end{array}$ & 79.49 & 86.89 & 79.49 & 86.89 & 84.0 \\
\hline $\begin{array}{l}\text { 0.5 }<\text { Culprit Score } \leq \mathbf{1 . 5} \text { to predict distal } \\
\text { RCA occlusion }\end{array}$ & 78.13 & 86.76 & 73.53 & 89.39 & 84.0 \\
\hline Culprit Score > 1.5 to predict LCX occlusion & 75.86 & 92.96 & 81.48 & 90.41 & 88.0 \\
\hline
\end{tabular}

PPV: Positive predictive value

NPV: Negative predictive value

The accuracy of some of the commonly used criteria to determine the infarct-related artery was tested in our study population. The criteria STE in III > II identifying RCA lesion had a sensitivity, specificity, positive and negative predictive values of $70.42 \%, 68.97 \%, 84.75 \%$ and $48.78 \%$, respectively.

The criteria of ST segment depression in lead avR $>0.1 \mathrm{mv}$ to localize LCX lesion was analyzed in our study population. It was found that sensitivity, specificity, positive and negative predictive values of $58.62 \%, 84.51 \%, 60.71 \%$ and $83.33 \%$, respectively. (Figure 4)

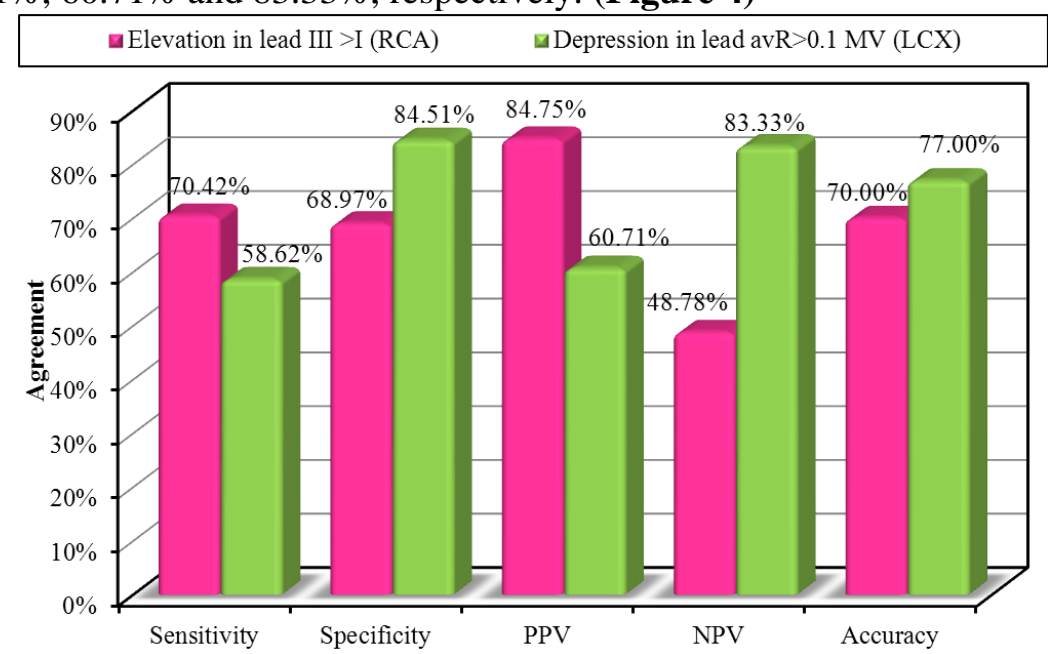

Figure (4): Sensitivity, specificity and predictive values of various ECG criteria in detection of

\section{Discussion}

In ST elevation myocardial infarction (STEMI), the first direct diagnosis is based on the surface electrocardiogram (ECG). The information obtained from the ECG provides the physician with an initial analysis of the patient's condition. It gives the physician directly the location of the infarction, its extent and basically the occluded artery ${ }^{(4)}$.

Various ECG criteria was suggested to identify the culprit artery in acute inferior wall
MI based on analysis of ST segment elevation and depression in ECG leads ${ }^{(5)}$.

It's extremely important to identify the site of RCA occlusion to determine the optimal treatment and management. Once we have determined by ECG with high probability that RCA is the occluded artery, we may use other ECG criteria to predict proximal versus distal RCA occlusion.

In the present study, we tested a new ECG algorithm (Culprit Score) to predict the 
culprit artery in inferior wall myocardial infarction.

The Culprit Score was used in this study to not only accurately identify the infarctrelated artery as RCA or LCX but also proximal or distal RCA lesions.

Evaluation of other various ECG criteria for prediction of the culprit artery and site of lesion in cases of inferior wall MI was also evaluated.

The axes of leads III and aVF have inferior direction, and therefore, STE is markedly seen in these leads in RCA occlusions. On the other hand, the leads I and $\mathrm{aVL}$ are directed laterally; therefore, STD are less evident in these leads in LCX artery occlusions ${ }^{(6)}$.

STD in precordial leads (V1-3) is commonly seen in inferior myocardial infarction, and caused either by reciprocal changes or various degrees of inferoposterior wall ischemia ${ }^{(7)}$.

The injury current vectors between anterior and posterior walls are more strongly opposed than that between anterior and inferior walls. Therefore, LCX occlusions produce more evident STD in precordial leads than distal or proximal RCA occlusion ${ }^{(14)}$.

Proximal RCA occlusion is known to be associated with STE in V1 owing to right ventricular infarction. The degree of STE was found to be significantly more in proximal as compared to distal RCA occlusions ${ }^{(8)}$.

Our hypothesis was the great variations in coronary anatomy amongst individuals, such as the relative size of vessels and the degree of dominance. Acute occlusion in a segment of the coronaries may not produce the "expected" changes in a particular lead because of other anatomical opposing factors. By combining several leads, the error caused by variations in a single lead may be minimized.

The cornerstone of Culprit Score [II $\mathrm{V} 2 / \mathrm{III}+\mathrm{V} 1$ - aVL] is the ratio of II/III suggested by $\boldsymbol{C h}$ ia et $\boldsymbol{a l} .{ }^{(\boldsymbol{9})}$. The leads that were found to be of important value (differentiate between RCA and LCX occlusion and between proximal and distal RCA occlusion) were either added to or subtracted from the numerator and/or the denominator. The subtraction of lead $\mathrm{V} 2$ from lead II in the numerator increases the influence of LCX occlusion; while the addition of lead V1 to and subtraction of lead aVL from lead III in the denominator increases the effect of proximal RCA occlusion and decrease that of distal RCA occlusion.

Regarding the identification of culprit lesion, culprit score identified 31 (79.5\%) cases with proximal RCA pattern, $25(78.1 \%)$ with distal RCA pattern, and $22(75.9 \%)$ with LCx pattern.

In this study, it was found that the sensitivity, specificity, positive predictive value (PPV) and negative predictive value (NPV) of the Culprit Score of $\leq 0.5$ determining proximal RCA lesion were $79.49 \%, 86.89 \%, 79.49 \%$, and 86.89 $\%$, respectively.

Similarly the corresponding values for Culprit Score of 0.5-1.5 for distal RCA lesions were $78.13 \%, 86.76 \%, 73.53 \%$, and $89.39 \%$, respectively.

When we calculated the Culprit Score for LCX artery lesion the corresponding values were $75.86 \%, 92.96 \%, 81.48 \%$, and $90.41 \%$, respectively.

The accuracy of some of the commonly used criteria was also tested in the study groups. It was found that the criteria STE in III > II identifying RCA occlusion had a sensitivity, specificity, positive predictive value (PPV) and negative predictive value (NPV) of $70.42 \%$, $68.97 \%, 84.75 \%, 48.78 \%$ respectively.

Similarly the sensitivity, specificity, positive predictive value (PPV) and negative predictive value (NPV) of the criterion that STD in lead avR $>0.1 \mathrm{mv}$ determining LCX lesion were $58.62 \%, 84.51 \%, 60.71 \%, 83.33 \%$ respectively.

Previous studies have already described different ECG signs to predict the infarctrelated artery. For example, (1) ST-segment depression in lead $\mathrm{I} \geq 0.5 \mathrm{~mm}$, (2) ratio of STsegment elevations in II/III < 1, (3) ratio of STsegment depressions in V3/ST-segment elevation in III < 1.2, (4) ST-segment elevation in V4R and (5) ST-segment depression in aVL $>$ I predicts RCA occlusion. By contrast (1) STsegment depression in lead avR $>1 \mathrm{~mm}$, (2) ratio of ST-segment elevation in II/III > 1 and (3) ratio of ST-segment depression in V3/STsegment elevation in III > 1.2 determines LCX lesion.

Regarding ST Segment elevation in lead III > II as a criterion of RCA lesion in patients with acute inferior wall MI, Wong et $\boldsymbol{a l}{ }^{(7)}$ studied 177 cases with the diagnosis of inferior wall myocardial infarction. ST Segment elevation in lead III > II had sensitivity of $(92 \%)$ and specificity of (64\%) for predicting RCA 
Assessment of validity of the 'Culprit Score' for predicting the culprit artery in patients...

occlusion with PPV and NPV of (90\%) and (70\%) respectively.

Similar results were also observed by Almansori et al. ${ }^{(10)}$. This study was conducted on 710 cases with the diagnosis of acute inferior wall MI who underwent primary PCI. They studied various ECG criteria to predict the culprit artery. For ST segment elevation in lead III > II as a predictor for of RCA occlusion, the sensitivity and specificity were $(86 \%)$ and (52\%) respectively with PPV and NPV of $(86 \%)$ and $(53 \%)$ respectively.

Regarding ST Segment depression in avR $>0.1 \mathrm{mv}$ as a criterion of LCX lesion in patients with acute inferior wall MI, Nair and Glancy, $2002^{(11)}$ were the first to suggest that the ST segment depression in lead aVR is associated with LCX rather than RCA involvement in inferior wall MI. They included 30 cases with acute inferior wall myocardial infarction. Coronary angiography was done within 7 days of the start of chest pain. It was found that the culprit artery was RCA in $83 \%$ of cases while LCX was the culprit artery in $17 \%$ of cases. In $80 \%$ of cases with ST segment depression $\geq 1 \mathrm{~mm}$ in lead aVR, the culprit artery was the LCX. Using ST segment depression $\geq 1 \mathrm{~mm}$ in aVR as a criterion to predict LCX as a culprit artery in patients with inferior wall MI, with sensitivity and specificity $69 \%$ and $91 \%$ respectively.

Small number of patients were included in this study particularly those with LCX occlusion (only 5 patients).

Kanei et al. ${ }^{(12)}$ studied 106 cases with the diagnosis of inferior wall MI where IRA was confirmed by coronary angiography. They found that the culprit artery was RCA in $81 \%$ while LCX in 19\% with 4.5:1 ratio. They found that $\mathrm{ST}$ depression in $\mathrm{aVR} \geq 1 \mathrm{~mm}$ was found in 11 patients i.e. in $53 \%$ of patients who had LCX as the IRA, and in 12 patients i.e. in $13 \%$ of patients who had RCA as the IRA. Using ST segment depression $\geq 1 \mathrm{~mm}$ in lead aVR for identifying LCX occlusion had a sensitivity and specificity of $53 \%$ and $86 \%$, with positive and negative predictive values of $45 \%$ and $91 \%$ respectively.

Regarding to these results, it could be said that the Culprit Score can be useful before doing angiography to accurately identify the site of the culprit lesion in cases with acute inferior wall MI.

\section{Conclusion}

We found that Culprit has a comparatively higher specificity, sensitivity and predictive values for identifying both RCA and LCX lesions as compared to the previously used criteria.

In conclusion, our new ECG algorithm could reliably predict the site of occlusion in inferior wall myocardial infarction.

\section{Limitations}

This study included 100 patients which are considered a small number, especially patients with LCx occlusion, which may affect the predictive values for ECG criteria.

Also, patients with non-documented history of previous myocardial infarctions were included.

\section{References}

1. Hartley A, Marshall DC, Salciccioli J et al.(2016): Trends in Mortality From Ischemic Heart Disease and Cerebrovascular Disease in Europe: 1980 to 2009. Circulation ,133(20):1916-26.

2. Tierala I, Nikus KC, Sclarovsky $\mathbf{S}$ et al.(2009):Predicting the culprit artery in acute ST-elevation myocardial infarction and introducing a new algorithm to predict infarct-related artery in inferior ST-elevation myocardial infarction: correlation with coronary anatomy in the HAAMU Trial. J Electrocardiol .,42(2):120-7.

3. Scanlon PJ, Faxon DP, Audet AM et al.(1999): ACC/AHA guidelines for coronary angiography. A report of the American College of Cardiology/ American Heart Association Task Force on practice guidelines (Committee on Coronary Angiography). J Am Coll Cardiol., 33(6):1756-824.

4. Engelen D, Gorgels A, Cheriex E et al.(1999): Value of the electrocardiogram in localizing the occlusion site in the left anterior descending coronary artery in acute anterior myocardial infarction. J Am Coll Cardiol., 34:389-395.

5. Verouden N, Barwari K, Koch $\mathrm{K}$ et al.(2009): Distinguishing the right coronary artery from the left circumflex coronary artery as the infarct-related artery in patients undergoing primary percutaneous coronary intervention for 
acute inferior myocardial infarction. Euro pace., 11: 1517-1521.

6. Herz I, Assali A, Adler Y et al.(1997): New electrocardiographic criteria for predicting either the right or left circumflex artery as the culprit coronary artery in inferior wall acute myocardial infarction. Am J Cardiol., 80:1343-1345.

7. Wong CK, Freedman SB, Bautovich G et al.(1993): Mechanism and significance of precordial ST-segment depression during inferior wall acute myocardial infarction associated with severe narrowing of the dominant right coronary artery. Am J Cardiol., 71:1025-1030.

8. Khan ZU, Chou TC.(1996): Right ventricular infarction mimicking acute anteroseptal left ventricular infarction. Am Heart J., 132:1089-1093.

9. Chia B, Yip J, Tan $\mathrm{H}$ et al.(2000): Usefulness of ST elevation II/III ratio and ST deviation in lead I for identifying the culprit artery in inferior wall acute myocardial infarction. Am J Cardiol., 86:341-343.

10. Almansori M, Armstrong $\mathrm{P}, \mathrm{Fu}$ Y et al.(2010): $\quad$ Electrocardiographic identification of the culprit coronary artery in inferior wall ST elevation myocardial infarction. Can J Cardiol., 26(6):293-296.
11. Nair R, Glancy D(2002): ECG discrimination between right and left circumflex coronary arterial occlusion in patients with acute inferior myocardial infarction: Value of old criteria and use of lead aVR. Chest, 122:134-139.

12. Kanei $Y$, Sharma J, Diwan $R$ et al.(2010): ST segment depression in aVR as a predictor of culprit artery and infarct size in acute inferior wall ST-segment elevation myocardial infarction. J Electrocardiol., 43(2):132-135.

13. Mohanty A, Saran $R K(2016)$ : Assessment of validity of the 'Culprit Score' for predicting the culprit lesion in patients with acute inferior wall myocardial infarction. Indian Heart Journal, 68(6):776-9.

14. Fiol M, Carrillo A(2010): Culprit artery in evolving inferior wall acute myocardial infarction: RCA vs LCx. Europace,12(5):758-.

15. Gabbiani G, Coen M(2013): Faculty of 1000 evaluation for Vasospasm of Atherosclerotic Coronary Arteries Precipitates Acute Ischemic Myocardial Damage in Myocardial Infarction-Prone Strain of the Watanabe Heritable Hyperlipidemic Rabbits. https://f1000.com/prime 